\title{
An Integrated Approach for Dynamic Charging of Electric Vehicles by Wireless Power Transfer - Lessons Learned from Real-Life Implementation
}

\author{
Ioannis Karakitsios and Evangelos Karfopoulos \\ National Technical University of Athens \\ Nikolay Madjarov \\ Technical University of Gabrovo \\ Aitor Bustillo \\ BATZ Sociedad Cooperativa \\ Marc Ponsar \\ Euroquality SARL \\ Dionisio Del Pozo \\ Tecnalia Research \& Innovation \\ Luca Marengo \\ Centro Ricerche Fiat SCPA
}

\begin{abstract}
The aim of this paper is to introduce a complete fast dynamic inductive charging infrastructure from the back-office system (EV management system) up to the Electric Vehicle (EV) (inductive power transfer module, positioning mechanism, electric vehicle modifications) and the EV user (User interface). Moreover, in order to assess the impact of the additional demand of inductive charging on the grid operation, an estimation of the 24-hour power profile of dynamic inductive charging is presented considering, apart from the road traffic, the probability of the need for fast charging, as well as the specifications of the proposed solution. In addition, an energy management system is presented enabling the management of the operation of the inductive charging infrastructure, the interaction with the EV users and the provision of demand response services to different stakeholders. The proposed dynamic inductive charging approach has been demonstrated within a real urban environment in order to provide useful insights regarding the experience gained from a real-field trial. The relevant practical conclusions are also discussed in this paper. Finally, a cost/benefit analysis, according to the Discounted Cash Flow (DCF) principles, is performed in order to assess the economic viability of the proposed solution.
\end{abstract}

CITATION: Karakitsios, I., Karfopoulos, E., Madjarov, N., Bustillo, A. et al., "An Integrated Approach for Dynamic Charging of Electric Vehicles by Wireless Power Transfer - Lessons Learned from Real-Life Implementation," SAE Int. J. Alt. Power. 6(1):2017, doi:10.4271/2017-01-9076.

\section{INTRODUCTION}

Fast inductive charging, can dramatically change the "usability" and attractiveness of electric vehicles to consumers by improving both the charging duration and the convenience offered. Even though wireless charging technology is rather premature, there are already some commercially available solutions enabling slow charging (i.e. $3.3 \mathrm{~kW}$ ) which are compatible with specific car models (e.g. Nissan, Siemens, Bosch/Evatran [1] etc).
The operational principle of the Inductive Power Transfer Module (IPTM) resembles to the one of transformers; transferring energy from a primary to a secondary coil (usually referred to as "pick-up coil") which are not physically connected as it is presented in [2] . In the majority of the IPTM designs proposed in the literature [ $[\underline{3}]-[\underline{12}]$, ferrite is usually implemented for reinforcing the magnetic flux. The experience from the early IPTM design of double sided couplers introduced in [ $\underline{3}]-[\underline{4}]$ indicated that the magnetic losses are increased and suppression issues of the field leakage are raised [ $\underline{5}$ ]. In order to overcome such issues, new IPTM topologies were proposed with circular coils placed above a ferrite layer or ferrite strips organized in a circular arrangement []]-[]]. The main disadvantages of such 
topologies are the very limited power transfer rate in case of a large air gap and their quite low tolerance concerning the horizontal misalignment. The Double-D or DD pad introduced in [ $\underline{5}]$, []], enables the transfer of a greater amount of power compared to circular pads, while the DDQ pad and the bipolar pad [ㅈ] -[]ㅡ, further increase the tolerance to misalignment.

Concerning dynamic inductive charging, two main design approaches exist. In the first one, the primary coil comprises a long coil going across a long ferrite track, while the secondary coil is much smaller. The design is characterized by the shape of the track it comprises, leading to the $\mathrm{E}, \mathrm{U}$ or $\mathrm{W}$-type coupler [10] , or the newly introduced I-type coupler [11]-[12]. In the second design approach, the on-route inductive charging system comprises several successively placed "segments" []ㅡ similar to the ones used in static inductive charging. The operation of each pad may be managed by separate power electronic interfaces increasing, thus, considerably the cost of such solution. In this respect, new control techniques have been proposed in the literature enabling the management of two or more pads by the same power electronic interface [13]-[14] .

In order to provide a high frequency current to the primary coil, the $\mathrm{AC}$ power provided from the grid is converted to a $\mathrm{DC}$ power source which is then converted to a high frequency current through a DC/AC converter. The alternating magnetic field induces an AC voltage on the receiving coil, which is finally rectified to provide a DC voltage to the battery of the EV. Many control schemes have been proposed either limited to the primary [15]-[17] or the secondary side [18][20], or applied to both sides of the IPT system [21]-[22]. In order to reduce the re-active power losses in the primary side and ensure a high output power and efficiency a compensation network is incorporated in the design. Depending on the way the capacitors are connected to the primary and secondary coils four basic topologies may exist: series-series (SS), series-parallel (SP), parallel-parallel (PP), parallel-series (PS) [2]. More complex methods for the compensation network have also been proposed in order to improve the tolerance to misalignment [23] $]$ [24 $]$. Variable tuning also appears as a compensation solution, allowing the control of the capacitance or inductance values [25] $-[\underline{26}]$.

The power transfer rate of an IPTM is subject to the relative positioning (i.e. vertical and horizontal misalignment) of the primary and secondary coils. Several approaches have been introduced aiming to achieve the optimal positioning of the Electric Vehicle and attain the maximum transfer power rate. The Unplugged project suggested a complicated positioning methodology of the vehicle with respect to an RFID system, a camera and the vehicle's odometry data [27]. The Primove project suggests a lifting and lowering mechanism which is only applicable for buses. Furthermore, there are several patents [28]-[31] related to the positioning system which, however, allow for limited lateral displacement and comprise heavy materials and components requiring large space of the EV. The positioning mechanism that was developed and is introduced in this paper, is a fully functional system designed for commercial vehicles, enabling the continuous charging of the EV at high power transfer rate considering a realistic air gap between the coils.
Besides the social benefits, the integration of fast inductive chargers into power systems raises new grid operational challenges to the system operators. The nominal installed capacity of a fast inductive charger can be high enough $(>30 \mathrm{~kW})$ resulting in a significant network load profile modification. The energy needs of dynamic inductive charging stations have been studied in [32]-[333], considering the traffic on the roads and based on theoretical scenarios regarding the operational characteristics of the stations, while a general scheme for the provision of real-time V2G services by

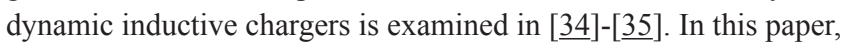
the power profile of dynamic inductive charging is estimated, considering parameters not just limited to road traffic, but also the probability of the need for fast charging, as well as the specifications of the proposed solution. An energy management system is also designed and developed in order to offer demand response services to the market operator in case of network operational issues arising due to the increased demand of the dynamic inductive charging stations.

The main contribution of the paper lies in the following aspects:

- It introduces a complete dynamic inductive charging system (IPTM design, IPTM control, positioning mechanism, energy management system)

- It provides an estimation of the additional charging demand which is expected to affect network operation.

- A cost/benefit analysis, according to the Discounted Cash Flow (DCF) principles, is performed in order to asses the economic viability of the proposed fast dynamic inductive charging solution.

The rest of the paper is organized as follows: The overall architecture and the specifications of each module of the proposed dynamic inductive charging system are presented in Section II. The proposed dynamic infrastructure is demonstrated in real urban environment and the results are discussed in Section III. Furthermore, the simulation tool and the results from the demand profile analysis of a dynamic inductive charging network are analysed in Section IV. Moreover, the conclusions of the Cost/Benefit analysis are presented in Section V. Finally, the paper concludes in $\underline{\text { Section VI. }}$

\section{PROPOSED FAST INDUCTIVE CHARGING CONCEPT}

\section{Overall System Architecture}

The main objective of the proposed fast dynamic inductive charging solution is to foster the democratization of EVs within the urban environment by developing a comfortable and easily implemented charging solution. Such a solution is expected to promote the use of EVs by the large public, while also facilitating their implementation in the urban grid.

The overall system architecture of the proposed fast inductive charging approach with the different modules and their interactions is illustrated in Figure 1. The black lines indicate the energy flow, while 
the information exchange is indicated by the red ones. The red line boxes indicate the services offered by the proposed dynamic wireless charging system.

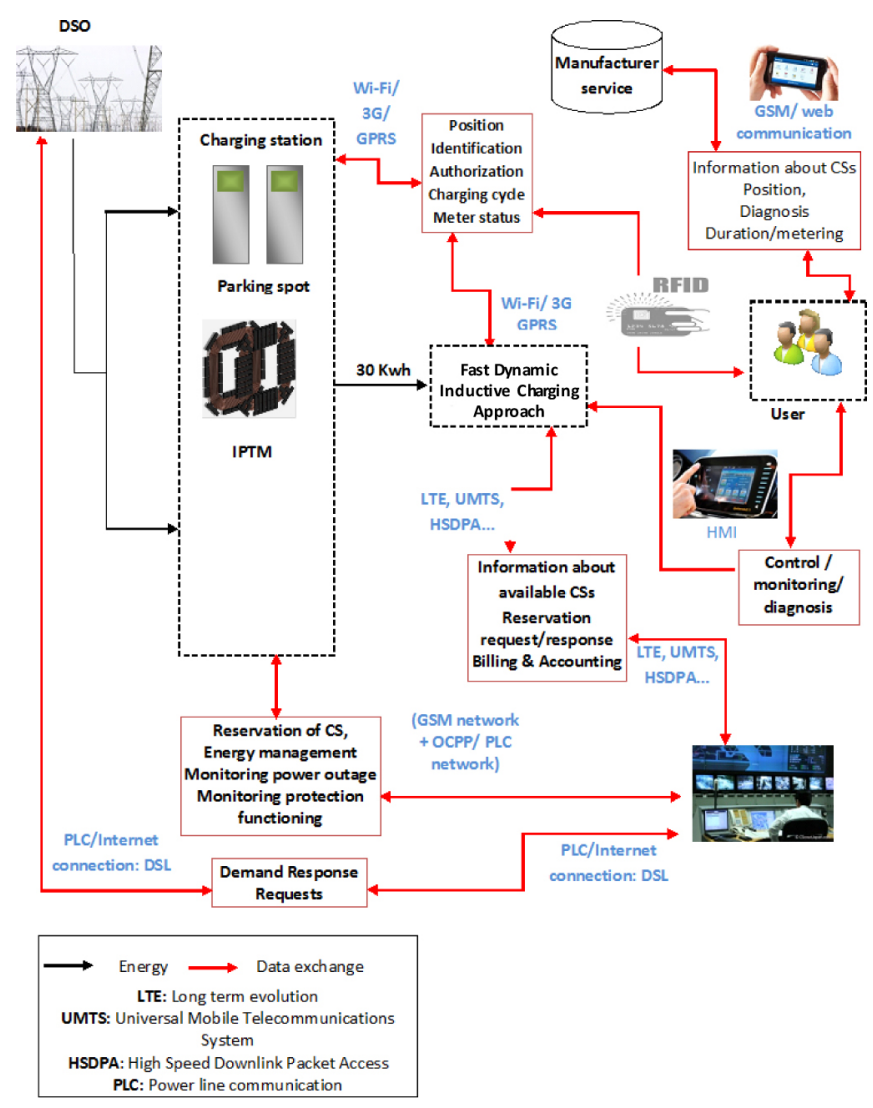

Figure 1. Overall view of the components and interfaces in the proposed fast dynamic inductive charging solution (Source: FastInCharge project)

\section{IPT Module}

The proposed dynamic inductive charging station, which is presented in Figure 2, comprises four successively placed primary coils. The power electronics topology consists of a common IGBT module and four IGBT modules, each one connected to one of the four primary coils (Figure 3 - [ㅌ6]). The common IGBT module is continuously enabled given that the charging station is in operation. Concerning the other four modules, they are enabled successively such that only one module operates each time forming a full bridge converter with the common module (Figure 3 ). In order to ensure the activation of one primary coil at a time, magnetic sensors are placed before each primary coil which are activated as the EV passes over them. In order to reduce the voltage applied in the primary coils and assure their galvanic isolation, the converter is connected to each one of the charging coils with a set of two parallel connected transformers TR3||TR4... TR9||TR10. Moreover, a series-series compensation scheme is applied to the design (CS3-CS4 ...CS9-CS10 for each one of the four primary coils). In order to reduce the high voltage across the compensation capacitors, a set of two capacitors (Csec1-Csec2 for the secondary coil) is used.

The frequency shift control method [ $\underline{36}]$ is adopted in the inverter allowing the control of the output parameters of the IPTM (voltage, current and power supplied to the battery) according to the air-gap and misalignment between the primary and the secondary coil. In order to efficiently allow greater variations in the high frequency voltage supplied by the converter, the phase shift PWM technique [36] is also incorporated in the design.

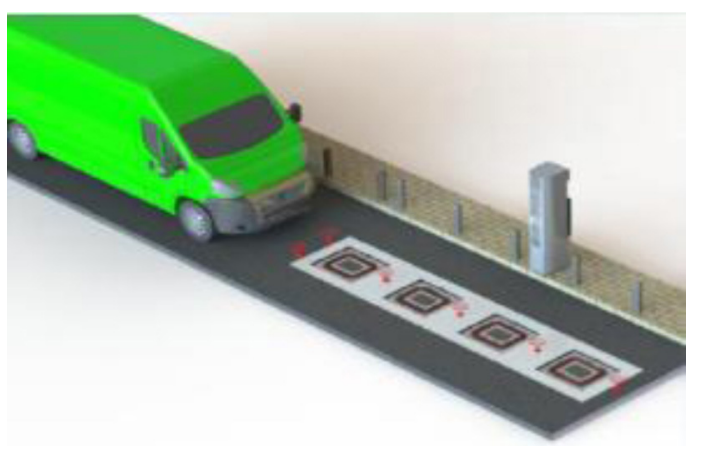

Figure 2. Fast dynamic inductive charging approach (Source: FastInCharge project)

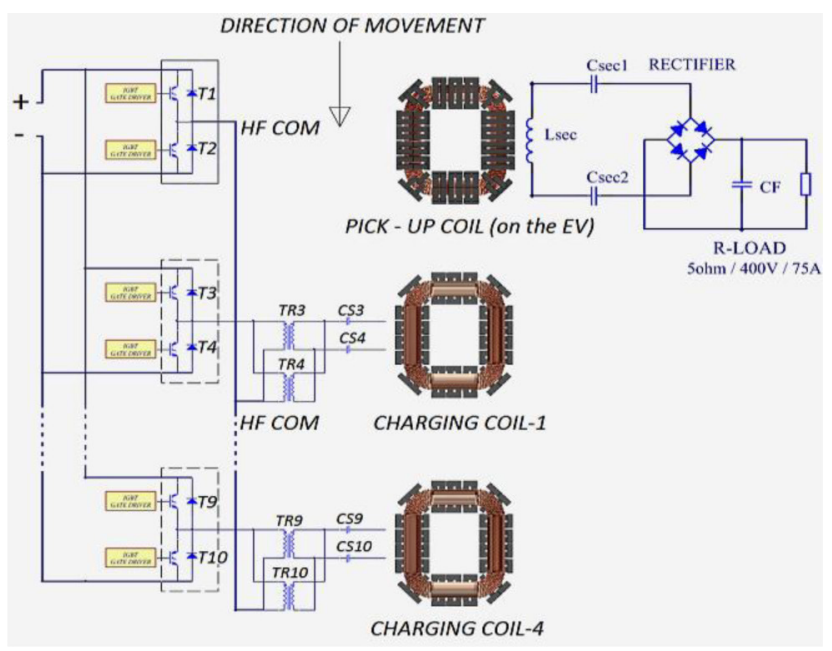

Figure 3. Power electronics topology of the inductive charging station

The IPT module is illustrated in Figure 4. Ferrite is adopted in the coil design in order to enhance and guide the magnetic flux. More specifically, MnZn ferrite plates are implemented due to their relatively high permeability, their excellent mechanical and electrical properties and the fact that they can be easily combined into many possible shapes. In addition, in order to reduce the increased conduction losses due to the high frequency required for the operation of the IPTM, litz wires are used in the design.
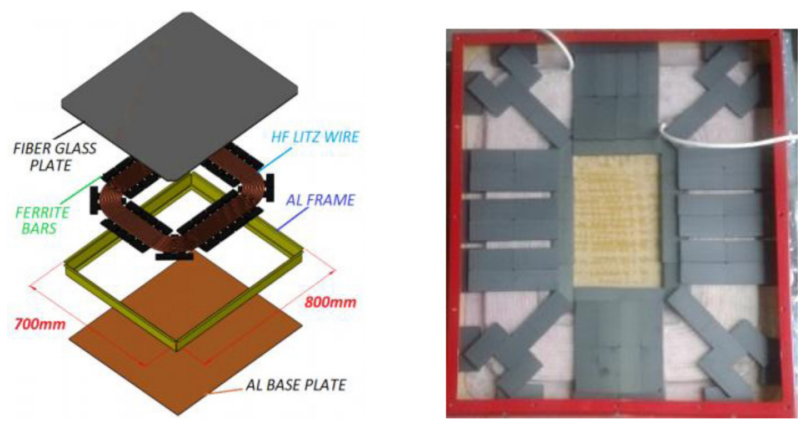

Figure 4. IPTM Coil construction (Source: FastInCharge project) 
Aluminum shielding is used in the proposed design in order to significantly reduce the emitted EM field, and improve the coefficient of the magnetic coupling between the transmitting and receiving side. In case of a horizontal misalignment between the primary and secondary coil, an asymmetric leakage of electromagnetic radiation can be observed Although the leakage close to the primary coil does not indicate any threat to objects or humans nearby, since the coil is buried underground, the leaked radiation close to the secondary coil could negatively affect nearby objects. Such results indicate that all elements close to the secondary winding, including the positioning mechanism, shall comprise nonmagnetic materials.

Based on simulations results examining various coil dimensions, it is concluded that when the horizontal misalignment is greater than one quarter of the winding size, the coupling coefficient, as well as the efficiency of the whole system significantly decreases. Furthermore, the maximum efficiency is inversely proportional to the air-gap; therefore, the operational air-gap of the IPT system must be selected very carefully. In this respect and in order for the IPTM to transfer a power of $30 \mathrm{~kW}$ at a horizontal misalignment of $\pm 20 \mathrm{~cm}$ and an air-gap of $80 \pm 10 \mathrm{~mm}$ (Figure 5), the dimensions for the primary and secondary winding were defined as " $700 \mathrm{~mm}$ x $800 \mathrm{~mm}$ x 90mm" and “700mm x 800mm x 60mm" respectively.

The proposed air-gap has been selected in order to ensure a high transferred power of $30 \mathrm{~kW}$, which is essential in the case of dynamic inductive charging, while maintaining a high efficiency of around $90 \%$. The selection of a greater air-gap is achievable, yet it would lead to a smaller system's efficiency as well as limited amounts of transferred power.

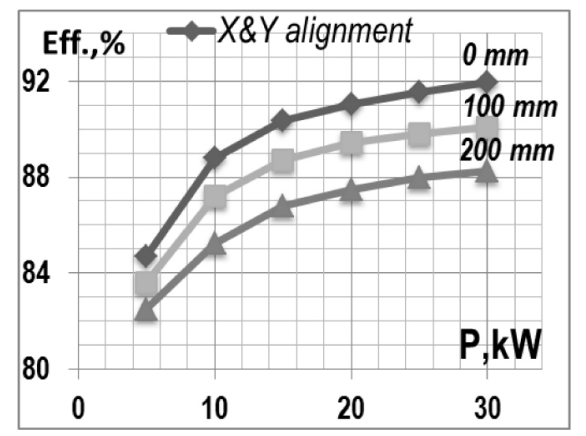

Figure 5. IPTM efficiency Vs. Output power and X\&Y alignment (Source: FastInCharge project)

The efficiency from the mains to the battery is $90-92 \%$. Therefore, the losses of the system are around 8 to $10 \%$ and are expected to be distributed among the high frequency (HF) inverter, the IPT module (comprising the primary and the secondary coil) and the output rectifier. More specifically, the losses for each specific module of the system are as follows:

a. HF inverter: $2-3 \%$;

b. IPT module: $5-6 \%$ :

- Primary: 3-4 \% (approximately $2 \%$ at wires and 2\% at the ferrite plates)

- Secondary: 2-3\% (approximately $1 \%$ at wires and $2 \%$ at the ferrite plates)

c. Output rectifier: $1-2 \%$
The power transferred to the vehicle while it moves over the station is expected to vary as depicted in Figure 6. Moreover, the technical specifications of the developed IPTM are tabularised in Table 1.

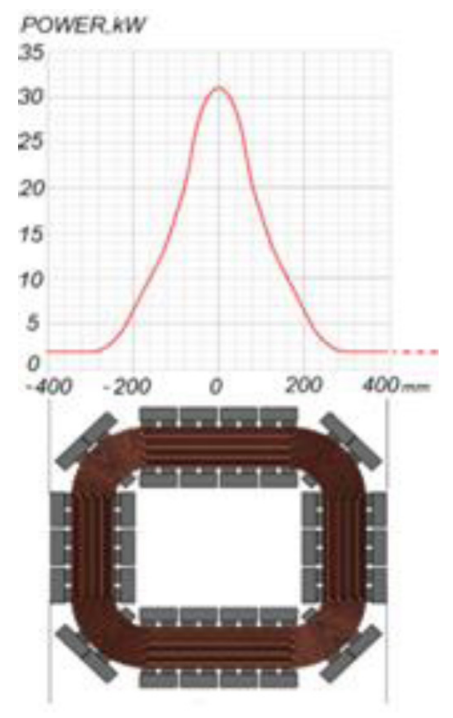

Figure 6. Power transferred to the vehicle while it moves over the station (Source: FastInCharge Project)

Table 1. Technical specifications of the IPTM

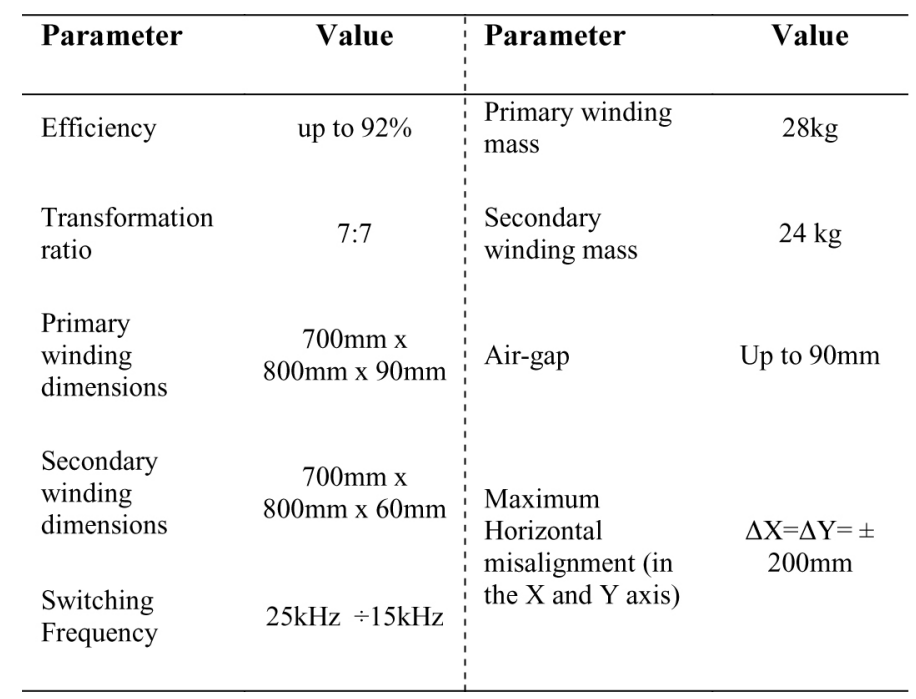

\section{Positioning Mechanism}

The air-gap of around $9 \mathrm{~cm}$ cannot be considered suitable for an EV while moving in roads not specifically designed for wireless dynamic charging. For this reason a positioning mechanism has been developed, which lowers the secondary coil when the EV moves over the charging station, in order to guarantee that the required air gap for wireless charging is achieved. The positioning mechanism lifts the secondary coil as soon as the EV moves away from the station to ensure the right clearance from the ground, while the EV moves in regular roads.

The mechanical system for the secondary coil was designed considering all the different elements that should be integrated in the demonstration electric vehicle i.e. the secondary coil and the AC-DC 
rectifier. A lightweight design for the positioning mechanism was considered as the main driver for the design, as it is illustrated in Figure 7.

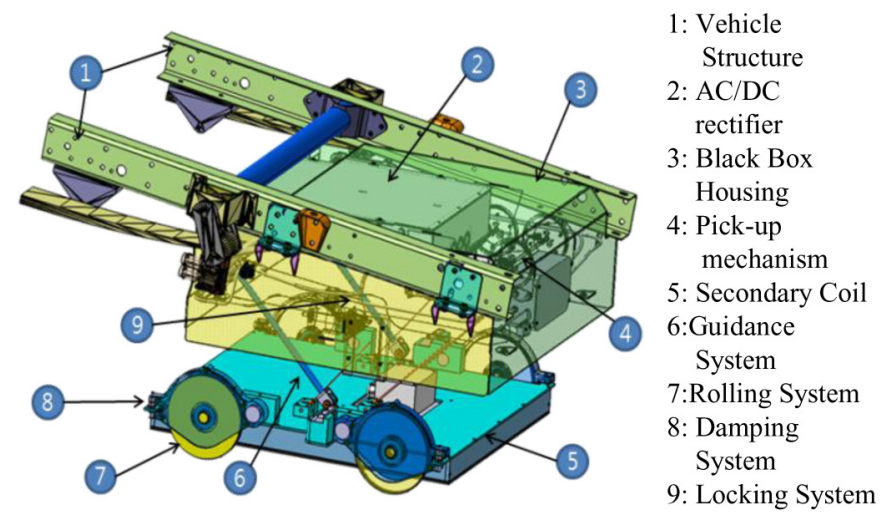

Figure 7. Secondary module integrated in the vehicle (Source: FastInCharge project)

The Vehicle structure (i.e. longitudinal parts related to the structure of the EV in which the design will be integrated) is considered in order to assemble the secondary module. The AC-DC rectifier for the secondary coil illustrated in Figure 3 is also integrated in the design.

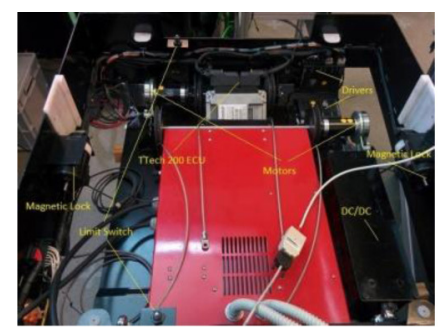

(a)

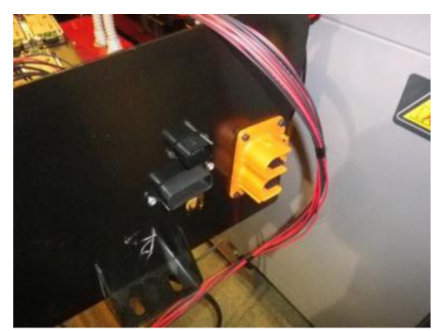

(b)
Figure 8. Black-box wires: a) Scheme of internal components wired; b) Connectors to EV (Source: FastInCharge project)

The Black-Box interconnects all internal devices (drivers, limit switch, electromagnetic blocks, motors, etc.), while also allowing the connection of those devices to the EV (Figure 8). It contains a system based on pulleys which is governed by two MAxon EC motors for vertical movement, coupled to the shaft with a GP52C 30NM 4ST gear and an ENC MILE 1600IMP 2K encoder (Figure 9a). A Locking System incorporating two electromagnetic solenoid blocks (Figure $\underline{9 b}$ ) has been used to lock the platform containing the secondary coil (integrated in the lower part of the secondary module) in the black-box housing. There is an ultrasonic sensor, which is necessary for the system to detect the ground during the downward movement is illustrated in Figure 9c. The control of the motion of the Black-box is performed by an Electronic Control Unit (ECU - TTTech, Figure 9d), which is programmed in MatLab ${ }^{\circledR}$-Simulink (with the addition of I/O Libraries for MPC555 and TTC 200), including the necessary functions to communicate via $\mathrm{CAN}$ bus with the $\mathrm{EV}$.

The Pick-Up Mechanism allows translations in the direction perpendicular to the vehicle movement in order to achieve the appropriate air-gap between the two coils. The motor and pulley system is accompanied with a Guidance System comprising a slider and guiding arms, so as to ensure a good positioning while the secondary coil is moving upwards. A Rolling System of 4 wheels has been implemented close to the secondary coil in order to ensure the functionality of the system while the EV is moving. The wheels are also provided with a Damping System which absorbs the roughness of the road, and minimizes the rolling noise.

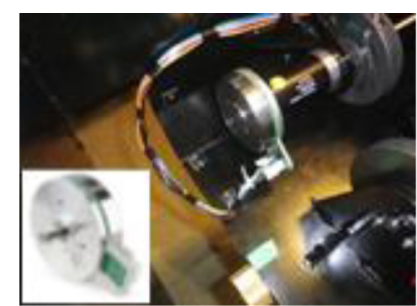

(a)

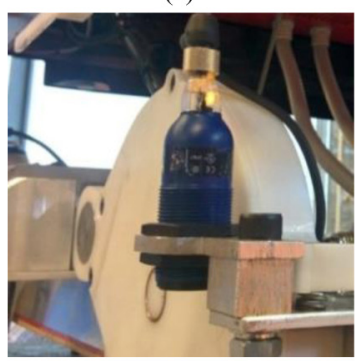

(c)

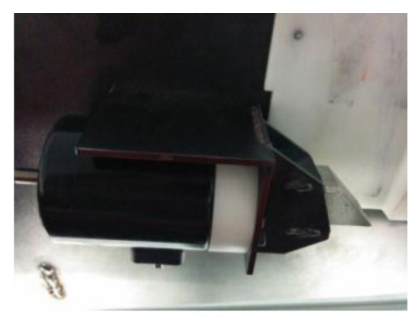

(b)

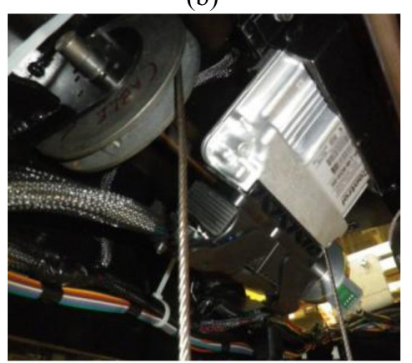

(d)
Figure 9. a) Maxon motor EC 90 flat with encoder and gearhead, b) Electromagnetic solenoid blocks, c) Ultra-sonic sensor, d) ECU TTTech 200 (Source: FastInCharge project)

\section{EV Modification}

One of the challenges of developing a complete fast dynamic inductive charging solution was the integration of the wireless charging device and all the related services to an existing vehicle, which is not specifically designed for this functionality. The battery characteristics and limits of a Light Commercial Vehicle (LCV) in $\mathrm{BEV}$ configuration were considered, in order to implement and optimize the design of the IPTM.

The electrical integration is based on the Electrical/Electronic (E/E) architecture of the baseline vehicle with the integration of the devices required to host the wireless charging (power devices and ancillary modules), as illustrated in Figure 10. The components coming from the original boardnet are just the powertrain components, namely the traction inverter and motor, the battery pack and the DC/DC converter.

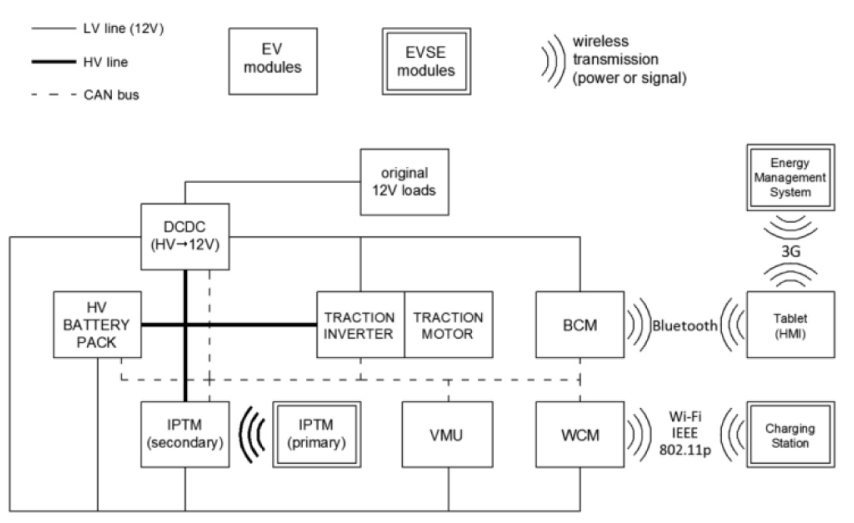

Figure 10. E/E architecture (focused on the High Voltage section and wireless charging) (Source: FastInCharge project) 
The modified architecture requires the addition of the wireless charging device, which incorporates in a single box the part of the IPT system to be installed in the EV and the positioning mechanism that controls the air-gap between the primary and the secondary coil.

On the Low Voltage (LV) side, a dedicated Vehicle Management Unit (VMU) is installed for interfacing the original vehicle's CAN bus with the new equipment, and coordinating the charging process on the vehicle side. A Wireless Communication Module (WCM) is also required, in order to establish a Wi-Fi communication channel between the EV and EV Supply Equipment (EVSE) side during the charging process. Concerning the interaction of the user with the charging device, a specific tablet-based HMI has been developed, communicating with the vehicle (via Bluetooth channel by means of a Bluetooth Communication Module - BCM), and with the management servers (via $3 \mathrm{G}$ channel).

\section{Energy Management System}

The overall system architecture of the energy management system developed for the proposed dynamic inductive charging approach is illustrated in Figure 11 [37]. The proposed management system can fit to any (static and dynamic) charging network since all functionalities are realized via web services, which can be easily updated or enhanced, and it adopts international standards for the interaction among different stakeholders.

More specifically, the energy management system is capable of offering the abovementioned services:

a. Monitoring the operation of the charging stations: The energy management system allows the operator of the charging stations to monitor the consumption of the charging stations in real-time. The interaction adopts the principles of OCPP protocol ${ }^{1}$

b. User awareness of the location, the availability and the electricity cost of the fast inductive charging stations: A graphical user interface has been developed in order to facilitate the interaction between the user interface and the energy management system. The user interface makes EV drivers aware of the locations and availability of the existing fast inductive charging infrastructures in order to be able to decide the most convenient place for charging their EV in respect to their trip destination. Finally, a pricing policy (multi-tariff pricing) should be adopted in order to incentivize charging during off-peak hours.

c. Remote control of the maximum charging rate of the stations under emergency network operational conditions: In case that the network operation is close to its capacity limits (equipment overloading) due to the increased demand of the fast inductive charging stations, the energy management system should enable the remote control of the maximum charging rate of the stations located at the specific part of the grid where the operational issue lies.

d. Offer booking services to EV owners enabling them to book the most suitable charging station at the most convenient time, considering their trip destination as well as the electricity energy prices. The service can be applied only in case of static charging.

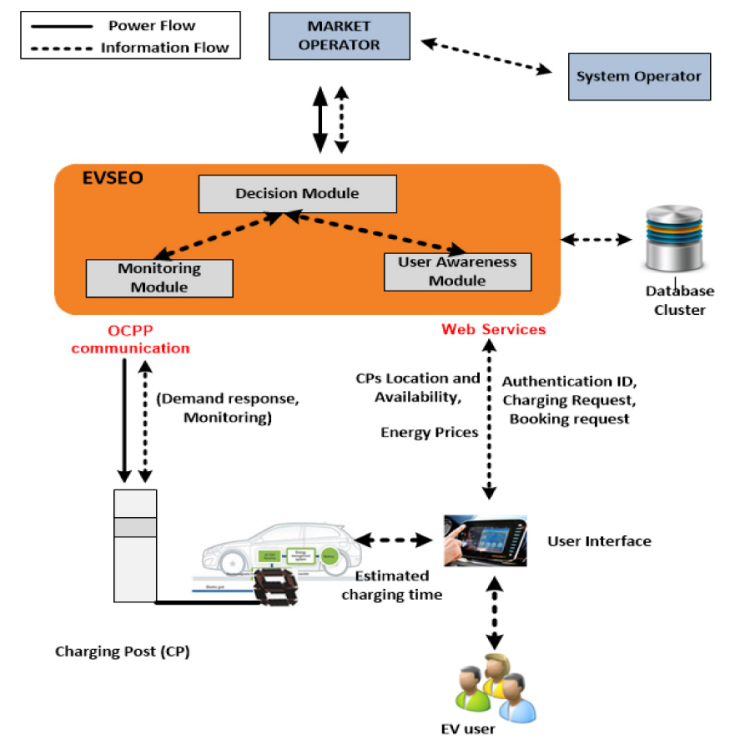

Figure 11. Overall outline of the energy management system (Source: FastInCharge project)

\section{DEMONSTRATION RESULTS}

The proposed fast dynamic inductive charging infrastructure has been successfully demonstrated in the city of Douai in France, in June 2015. The demonstration results regarding each component of the infrastructure are presented in detail in the following sub-sections.

\section{IPT Module}

The proposed dynamic inductive charging station with the four primary coils "buried" in a road of Douai city (France) is illustrated in Figure 12. Since the transferred power and efficiency greatly depend on the misalignment between the primary and the secondary coils, the optimal charging path was marked by white lines (Figure 12) assisting EV users for the correct coils placement while driving.

The demonstration of inductive charging was performed at a maximum vehicle speed of $15 \mathrm{~km} / \mathrm{h}$ and the obtained results are presented in Table 2. Although the charging infrastructure is capable of providing $30 \mathrm{~kW}$ to the vehicle, due to EV battery operational constraints, an average power of $23.73 \mathrm{~kW}$ was achieved during the demonstration.

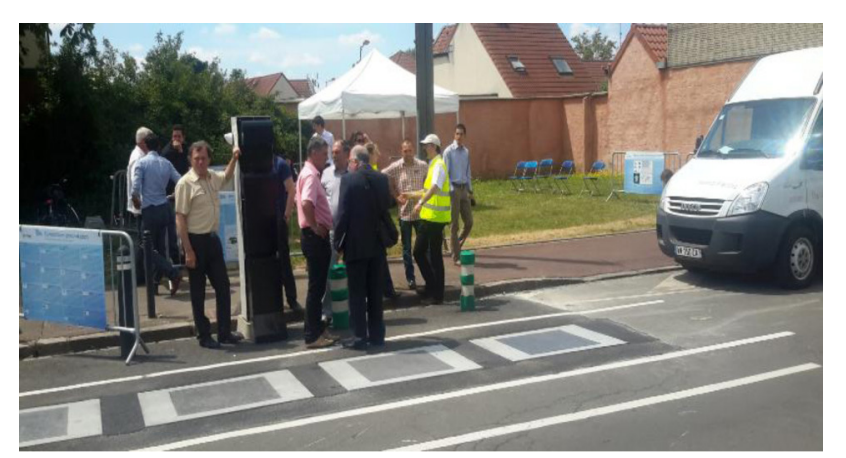

Figure 12. Dynamic inductive charging installed in Douai, France. (Source: FastInCharge project) 
Table 2. Average Results for the charging coils in the dynamic charging station.

\begin{tabular}{lc}
\hline Parameter & Value \\
\hline Input power (kW) & 26.18 \\
Battery DC voltage (V) & 349 \\
Charging DC current (A) & 68 \\
Battery charging power (kW) & 23.73 \\
Efficiency (\%) & 90.65 \\
\hline
\end{tabular}

Concerning the electromagnetic safety, the magnetic flux density was measured equal to $13.8 \mu \mathrm{T}$ at a distance of $60 \mathrm{~cm}$ from the center of the primary coil (Figure 13), which is well below the limits set by the ICNIRP guidelines $(27 \mu \mathrm{T}$ and $100 \mu \mathrm{T}$ for the general public and the occupational exposure to EM fields respectively) [38]. The magnetic flux density is further reduced when considering a greater distance from the center of the coil (Figure 13).

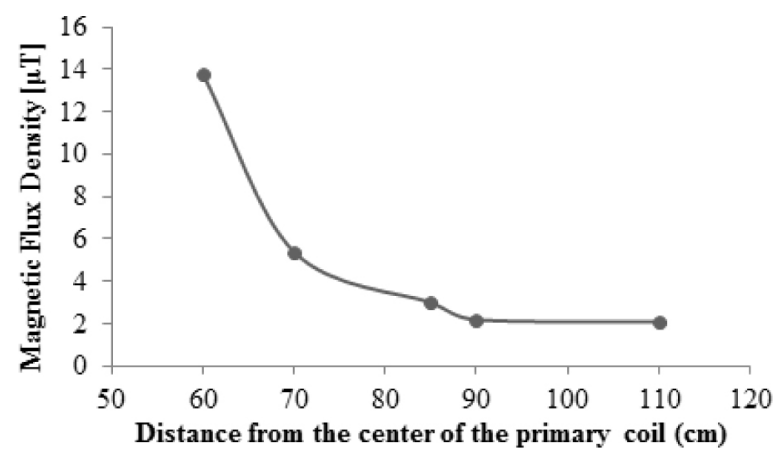

Figure 13. Magnetic flux density measured at various distances from the center of the primary coil

\section{Position Mechanism}

The demonstrated positioning mechanism is displayed in Figure 14. The positioning mechanism, alongside with the secondary coil, was installed at the rear end of the vehicle (Figure 14a). As soon as the vehicle approaches the station and when charging is requested by the EV user, the secondary coil is lowered until the required air-gap with the primary coil is achieved (Figure 14b).

The positioning mechanism was installed in a commercial vehicle in order to transfer high amounts of power, requiring, quite a small air-gap as well as a large secondary coil. A positioning system, however, with such dimensions and weight is not suitable for passenger cars. Nevertheless, in the case of light passenger vehicles, the EV battery capacity is much lower than the one demonstrated. Thus, lower charging power transfer rates can be accepted. It was determined that a reduction of around $39 \%$ in the dimensions of the secondary coil, which is translated in a charging power rate of $25 \mathrm{~kW}$, makes this solution also suitable for lighter passenger cars. The proposed positioning mechanism can be further improved by incorporating it in the damping system of the EV without significant modifications.

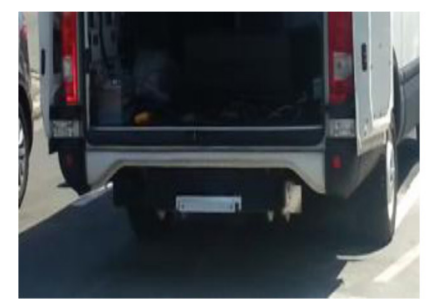

(a)

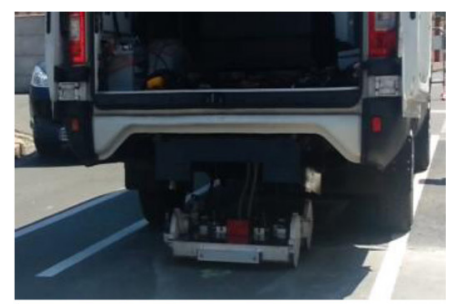

(b)
Figure 14. Positioning mechanism in the (a) up and (b) down position (Source: FastInCharge project)

\section{Energy Management System}

The user interface for the energy management system is illustrated in Figure 15.

The left-hand picture in Figure 15 shows the first screen of the user-interface which makes EV users aware of the location of the charging stations and their availability via the colour- indexing (green-available, orange-unavailable and red-not in operation). The right-hand picture in Figure 15 provides more details for each station separately enabling EV user to book available timeslots (15-minutes) for charging.
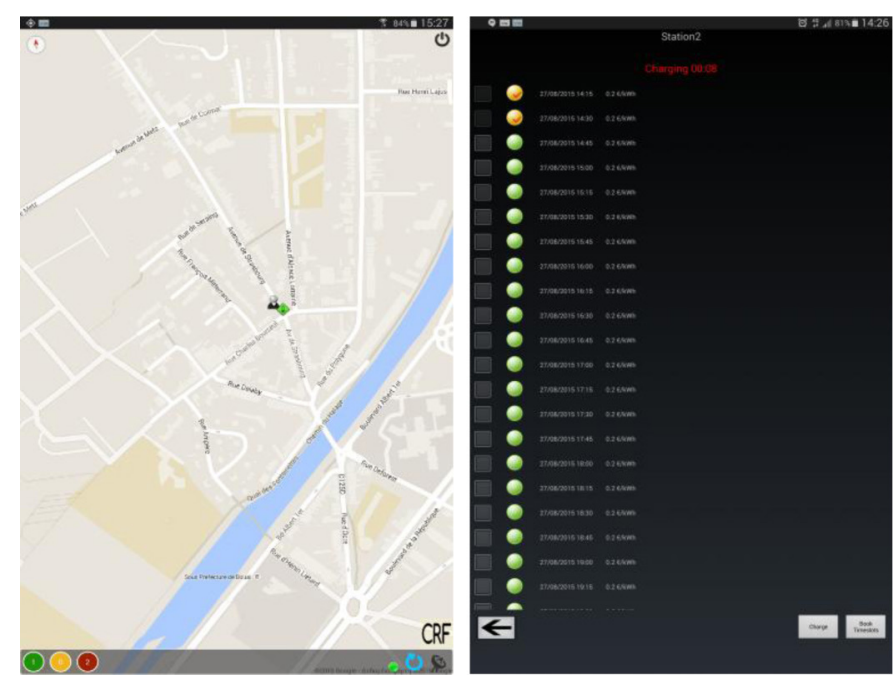

Figure 15. User interface of the energy management system (Source: FastInCharge project)

\section{POWER DEMAND PROFILE OF DYNAMIC INDUCTIVE CHARGING}

In order to define the dynamic inductive charging needs, two parameters are taken into account: 1) the need for fast charging and 2 ) the mobility pattern. The first parameter is simulated via the distribution function illustrated in Figure 16a [푹, based on data from real fast conductive chargers. The mobility pattern in Figure 16b is defined based on the official data published from the transport department of Great Britain². 


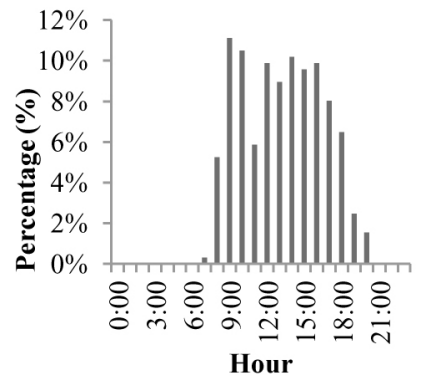

(a)

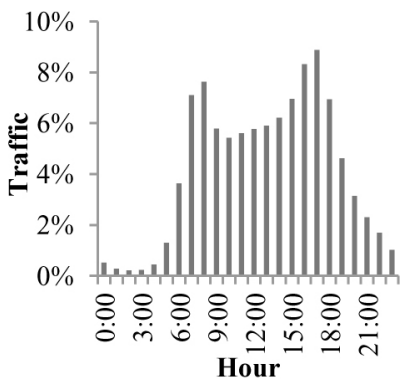

(b)
Figure 16. Parameters to define the demand of dynamic inductive charging: (a) charging needs and (b) Percentage of vehicles moving on the roads.

Based on the aforementioned parameters and the input charging power in Table 2, the load profile for different numbers of inductive charging stations is presented in Figure 17. It is concluded that a quite high demand is introduced during the morning and middle day hours. In case that the charging demand peak (for instance 3.9MW in case of 150 stations) is synchronized with the high domestic consumption, grid operational issues may be noticed, such as network equipment overload, requesting grid reinforcement. The demand response services offered by the proposed energy management system are capable of preventing/postponing premature grid investments.

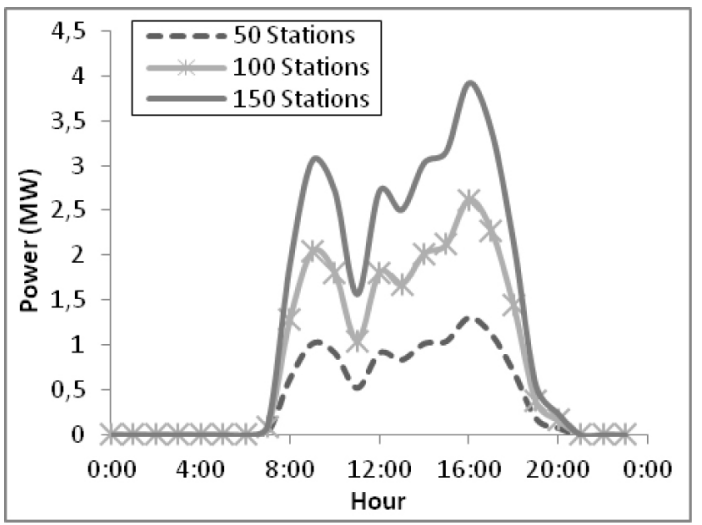

Figure 17. Power demand profile considering the case of 50, 100 and 150 dynamic inductive charging stations installed in the grid.

\section{COST/BENEFIT ANALYSIS}

In order to assess the economic viability of the proposed fast dynamic inductive charging solution, a cost/benefit analysis is performed based on the principles of the Discounted Cash Flow (DCF) approach. Since fast dynamic inductive charging is a premature technology, complicated evaluation methods are not appropriate for the cost benefit analysis. Thus, the free cash flow approach is adopted which is a trustworthy measure that almost eliminates the arbitrariness and "guesstimates" involved in reported earnings. Regardless of whether a cash outlay is counted as an expense or turned into an asset on the balance sheet, free cash flow tracks the money left over for investors.
A realistic scenario of 5\% of growth in the first year and up to $20 \%$ of growth in the fifth year is considered. Such a scenario shall not be regarded as a risky one, since Frost\&Sullivan have predicted an annual growth for inductive charging market of $126.6 \%$ from 2012 to $2020^{3}$. The discount rate is set at $7.10 \%$, which is the cost of equity that has been calculated. Considering a decrease of operating costs every year, and an investment made every two years, the Net Present Value (NPV) calculated for the first year is $-940,400 €$. A positive NPV is reached in year 12, which indicates the time that the project becomes profitable.

Considering a probability of 50 and $60 \%$ for the accurate forecast of the benefits and costs respectively, the Benefit Cost Ratio (BCR) reaches 2.5 in 15 years, meaning that for a euro invested, $2.5 €$ is earned. Furthermore after the 5th year, the BCR is stable and increasing, indicating the time that the project will become profitable.

A sensitivity analysis has also been performed taking into account the parameters that are most likely to change during the project: the net investment, the operating costs and the electricity price. The analysis suggests that the terminal value is affected by the net investment, as an increase of $40 \%$ in the net investment decreases the terminal value by $16 \%$. Furthermore, an increase of $25 \%$ or $10 \%$ in the operating costs or the electricity price, respectively, reduces the NPV by $8 \%$. In the aforementioned cases, the break-even point is reached during year 14 instead of 12, which can still be considered as an acceptable alternative.

\section{CONCLUSIONS}

A complete dynamic inductive charging solution has been developed, comprising the IPT module, which allows the transfer of $30 \mathrm{~kW}$ of power at an air-gap of up to $9 \mathrm{~cm}$ and a maximum misalignment of $20 \mathrm{~cm}$. Moreover, the proposed positioning mechanism successfully proved to assure the operation of the system at the desired air-gap. Regarding the EV side, modifications shall be made to the $\mathrm{E} / \mathrm{E}$ architecture of the baseline vehicle, in order to incorporate the power devices and ancillary modules related to wireless charging. The load profile analysis implied that the additional charging demand can significantly modify system demand profile in case of mass deployment. However, the proposed energy management system can effectively address this issue, by adjusting the charging power rate of specific charging stations located within the problematic grid area. The cost/benefit analysis that was performed indicates that the project can become profitable, even in the case where versatile parameters, like the net investment, the operating costs and the electricity price, are considered.

Although the proposed positioning mechanism was developed for a commercial vehicle, appropriate modifications to reduce its size, alongside with alternative techniques to ensure the desired air-gap, suggest the use of the system in passenger cars.
3. http://www.frost.com/sublib/frost-content.do?sheetName=reportoverview\&sheetGroup=M9B8-01-00-00-00\&viewName=virtual-brochure\&repid=M 9B8-01-00-00-00 
Karakitsios et al / SAE Int. J. Alt. Power. / Volume 6, Issue 1 (May 2017)

\section{REFERENCES}

1. Carlson, R. and Normann, B., "Test Results of the PLUGLESSTM Inductive Charging System from Evatran Group, Inc.," SAE Int. J. Alt. Power. 3(1):64-71, 2014, doi:10.4271/2014-01-1824.

2. Chwei-Sen Wang, Stielau, O.H., and Covic, G.A.: 'Design considerations for a contactless electric vehicle battery charger', IEEE Trans. on Ind. Electronics, Volume: 52, Issue: 5, pp. 1308 - 1314, 2005, doi: 10.1109/TIE.2005.855672

3. Nagatsuka, Y., Ehara, N., Kaneko, Y., Abe, S., et al.: 'Compact contactless power transfer system for electric vehicles', International Power Electronics Conference (IPEC), 2010, pp. 807-813, doi: 10.1109/ $\underline{\text { IPEC.2010.5543313 }}$

4. Chigira, M., Nagatsuka, Y., Kaneko, Y., Abe, S., et al.: 'Small-Size Light-Weight Transformer with New Core Structure for Contactless Electric Vehicle Power Transfer System', Energy Conversion Congress and Exposition (ECCE), 2011, pp. 260-266, doi: 10.1109/ ECCE.2011.6063778

5. Covic, G.A., and Boys, J.T.: 'Modern Trends in Inductive Power Transfer for Transportation Applications', Emerging and Selected Topics in Power Electronics, IEEE Journal of, Volume: 1, Issue: 1, 2013, pp. 28 - 41, doi: 10.1109/JESTPE.2013.2264473

6. Mecke R. and Rathge C., "High frequency resonant inverter for contactless energy transmission over large air gap," in Power Electronics Specialists Conference, 2004. PESC 04. 2004 IEEE 35th Annual, 2004, pp. 1737-1743 Vol.3, doi: 10.1109/PESC.2004.1355378

7. Budhia, M., Covic, G.A, and Boys, J.T: 'Design and optimization of magnetic structures for lumped inductive power transfer systems' IEEE Trans. Power Electron. Soc., vol. 26, no. 11, Nov. 2011, pp. 3096-3108, doi: 10.1109/TPEL.2011.2143730

8. Budhia, M., Boys, J.T, Covic, G.A, and Chang-Yu, H.: 'Development of a Single-Sided Flux Magnetic Coupler for Electric Vehicle IPT Charging Systems', Industrial Electronics, IEEE Transactions on, vol. 60, 2013, pp. 318-328, doi: 10.1109/TIE.2011.2179274

9. Covic, G.A, Kissin, M.L.G., Kacprzak, D., Clausen, N., et al.: 'A bipolar primary pad topology for EV stationary charging and highway power by inductive coupling', Energy Conversion Congress and Exposition (ECCE), 2011, pp. 1832-1838, doi: 10.1109/ECCE.2011.6064008

10. Sungwoo, L., Jin, H., Changbyung, P., Nam-Sup, C., et al.: 'On-Line Electric Vehicle using inductive power transfer system' in Energy Conversion Congress and Exposition (ECCE), 2010, pp. 1598-1601, doi: 10.1109/ECCE.2010.5618092

11. Choi, S.Y., Jeong, S.Y., Lee, E.S., Gu, B.W., et al.: 'Generalized Models on Self-decoupled Dual Pick-up Coils for Large Lateral Tolerance' Power Electronics, IEEE Transactions on, Nov. 2015, pp. 6434 - 6445, doi: 10.1109/TPEL.2015.2399938

12. Huh J., Lee S. W., Lee W. Y., Cho G. H., et al. "Narrow-Width Inductive Power Transfer System for Online Electrical Vehicles," Power Electronics, IEEE Transactions on, vol. 26, pp. 3666-3679, 2011, doi: $\underline{\text { 10.1109/TPEL.2011.2160972 }}$

13. Nagendra, G. R., Boys, J.T, Covic, G.A, Riar, B. S., et al.: 'Design of a double coupled IPT EV highway', Industrial Electronics Society, IECON, 39th Annual Conference of the IEEE, 2013, pp. 4606-4611, doi: $\underline{10.1109 / \text { IECON.2013.6699878 }}$

14. Lee, K., Pantic, Z., and Lukic, S.: 'Reflexive Field Containment in Dynamic Inductive Power Transfer Systems', Power Electronics, IEEE Transactions on, 2013, doi: 10.1109/TPEL.2013.2287262

15. Esteban, B.; Sid-Ahmed, M.; Kar, N.C.:"A Comparative Study of Power Supply Architectures in Wireless EV Charging Systems", Power Electronics, IEEE Transactions on, pp: 6408 - 6422, 2015, doi: $10.1109 /$ TPEL.2015.2440256

16. Xiaohui Qu; Hongdou Han; Siu-Chung Wong; Tse, C.K. et al.: 'Hybrid IPT Topologies With Constant Current or Constant Voltage Output for Battery Charging Applications', IEEE Trans. on Power Electronics, vol. 30, issue 11, pp. 6329 - 6337, 2015, doi: 10.1109/TPEL.2015.2396471

17. Hua Cai; Liming Shi; Yaohua Li: 'Harmonic-Based Phase-Shifted Control of Inductively Coupled Power Transfer', IEEE Trans. on Power Electronics, Vol. 29, issue 2, pp. 594-602, 2014, doi: 10.1109/ TPEL.2013.2257865

18. Huang, C.Y.; Boys, J.T.; Covic, G. A.: 'LCL Pickup Circulating Current Controller for Inductive Power Transfer Systems', IEEE Trans. on Power Electronics, Vol. 28, Issue: 4, pp. 2081 - 2093, 2013, doi: $\underline{10.1109 / \text { TPEL.2012.2199132 }}$
19. Keeling, N.A.; Covic, G.A.; Boys, J.T.: 'A Unity-Power-Factor IPT Pickup for High-Power Applications', IEEE Trans. On Industrial Electronics, vol. 57, Issue:2, pp. 744-751, 2010, doi: $\underline{10.1109 /}$ TIE.2009.2027255

20. Wu, H.H.; Boys, J.T.; Covic, G.A.: 'An AC Processing Pickup for IPT Systems', IEEE Trans. on Power Electronics, vol. 25, issue: 5, pp. 1275 1284, 2010, doi: 10.1109/TPEL.2009.2037002

21. Diekhans, T.; De Doncker, R.W.: 'A Dual-Side Controlled Inductive Power Transfer System Optimized for Large Coupling Factor Variations and Partial Load', IEEE Trans. on Power Electronics, vol. 30, issue 11, pp.6320-6328, 2015, doi: 10.1109/TPEL.2015.2393912

22. Wu, H.H.; Gilchrist, A.; Sealy, K.D.; Bronson, D.: 'A High Efficiency $5 \mathrm{~kW}$ Inductive Charger for EVs Using Dual Side Control', IEEE Trans. on Industrial Informatics, vol. 8, issue 3, pp. 585-595, 2012, doi: $\underline{10.1109 / \text { TII.2012.2192283 }}$

23. Fei Lu; Hua Zhang; Hofmann, H.; Mi, C.: 'A Double-Sided LCLCCompensated Capacitive Power Transfer System for Electric Vehicle Charging', IEEE Trans. on Power Electronics, vol. 30, issue 11, pp. 6011 - 6014, 2015, doi: 10.1109/TPEL.2015.2446891

24. Villa J. L., Sallan J., Sanz Osorio J. F., and Llombart A., "HighMisalignment Tolerant Compensation Topology For ICPT Systems," Industrial Electronics, IEEE Transactions on, vol. 59, pp. 945-951, 2012, doi: $\underline{\text { 10.1109/TIE.2011.2161055 }}$

25. Iguchi, S.; Pyungwoo Yeon; Fuketa, H.; Ishida, K. et al.: 'Wireless Power Transfer With Zero-Phase-Difference Capacitance Control', IEEE Trans. on Circuits and Systems I: Regular Papers, vol. 62 issue 4, pp. 938-947, 2015, doi: 10.1109/TCSI.2015.2388832

26. Keeling, N.; Covic, G.A.; Hao, F.; George, L. et al.: 'Variable tuning in LCL compensated contactless power transfer pickups', Energy Conversion Congress and Exposition (ECCE), pp. 1826-1832, 2009, doi: 10.1109/ECCE.2009.5316169

27. Hudece J., Kufen J., Langen O., Dankerty J., et al. “A System for Precise Positioning of Vehicles Aiming at Increased Inductive Charging Efficiency", MedPower Conference, Athens, Nov. 2014, doi: 10.1049/ cp.2014.1661

28. Ling-Yuan Tseng, "Electric vehicle pick-up position control", Patent US5595271 A, January 21, 1997

29. Dongho Cho, In Soo Suh, Ryu Byung Youk, Yun Jung, et al. "System and method for controlling vertical movement of power acquisition device mounted on non-contact electromagnetic induction charging-type electric vehicle", Patent WO2011046407 A2, April 21, 2011.

30. Bertrand Desire, Sonja Boedt, Stefan Lischke: "Inductive pickup arrangement for an electric vehicle and method of operating an electric vehicle", Patent WO2013167757 A2, November 14, 2013.

31. Jan Kiszka, "System for the short-term charging of electrically operated vehicles", Patent WO2012126726 A3, January 13, 2013.

32. Stamati, T.-E.; Bauer, P. , "On-road charging of electric vehicles", Transportation Electrification Conference and Expo (ITEC), 2013, Pp. 1-8, doi: 10.1109/ITEC.2013.6573511

33. Stamati, T.-E.; Bauer, P., "Green energy for on-road charging of electric vehicles", Mechatronika, 15th International Symposium, Pp. 1-9, 2012

34. Javanbakht, P.; Mohagheghi, S.; Parkhideh, B.; Dutta, S. et al. "Vehicle-to-grid scheme based on inductive power transfer for advanced distribution automation", Energy Conversion Congress and Exposition (ECCE), 2013 IEEE, pp. 3250-3257, 2013, doi: 10.1109/ ECCE.2013.6647127

35. Mohagheghi, S.; Parkhideh, B.; Bhattacharya, S., "Inductive power transfer for electric vehicles: Potential benefits for the distribution grid", Electric Vehicle Conference (IEVC), 2012 IEEE International, pp. 1-8, 2012, doi: 0.1109/IEVC.2012.6183266

36. Erickson R. W., Maksimovic D., "Fundamentals of Power Electronics", Kluwer Academic Publishers, NJ, USA, 2000, doi: 10.1007/b100747

37. Karfopoulos E., Hatzoplaki E., Safalidis G., Karakitsios I., et al. "Energy Management System for fast inductive charging network: The FastInCharge project", MedPower Conference, Athens, Nov. 2014, doi

38. ICNIRP Guidelines for Limiting Exposure to Time-Varying Electric, Magnetic and Electromagnetic Fields (1-100kHz), Health Physics, 2010, doi: $10.1049 /$ cp.2014.1664

39. Karakitsios I., Karfopoulos E., Hatziargyriou N., "Static and Dynamic Fast Inductive Charging: The FastInCharge project concept", MedPower Conference, Athens, Nov. 2014, doi: 10.1049/cp.2014.1663 


\section{CONTACT INFORMATION}

Ioannis Karakitsios

National Technical University of Athens

Work Phone: 0030 - 2107723696

jkarak@power.ece.ntua.gr

\section{ACKNOWLEDGMENTS}

This work was supported by the European Commission within the framework of the 7th Framework Programme, Project FastInCharge under the Grant Agreement: 314284.

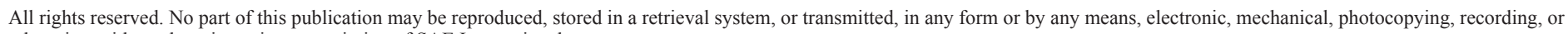
otherwise, without the prior written permission of SAE International.

Positions and opinions advanced in this paper are those of the author(s) and not necessarily those of SAE International. The author is solely responsible for the content of the paper. 